Category

Synthesis of

Materials and

Unnatural Products

\section{Key words}

2D acenes

heteroacenes

photostability

Z. WANG, J. LI, S. ZHANG, Q. WANG, G. DAI, B. LIU, X. ZHU, Z. LI, C. KOLODZIEJ,

C. MCCLEESE, C. BURDA, W. SUN*, L. CHEN* (TIANJIN UNIVERSITY, P. R. OF CHINA AND NORTH DAKOTA STATE UNIVERSITY, FARGO, USA)

Stable 2D Bisthienoacenes: Synthesis, Crystal Packing, and Photophysical Properties

Chem. Eur. J. 2018, 24, 14442-14447.

\title{
2D Heteroacenes: New Building Blocks for Organic Materials
}

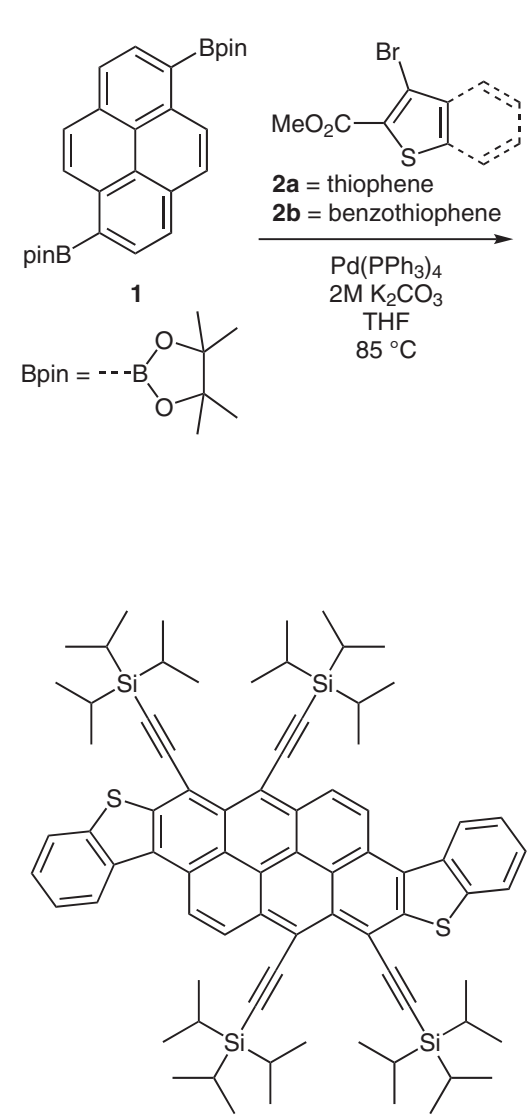

6b, $10 \%$ yield<smiles>COC(=O)c1sc2ccccc2c1-c1ccc2c3c1ccc1ccc4c(c13)=C(C=C2)C=4c1c(C(C)=O)sc2ccccc12</smiles><smiles></smiles>

6a, $19 \%$ yield

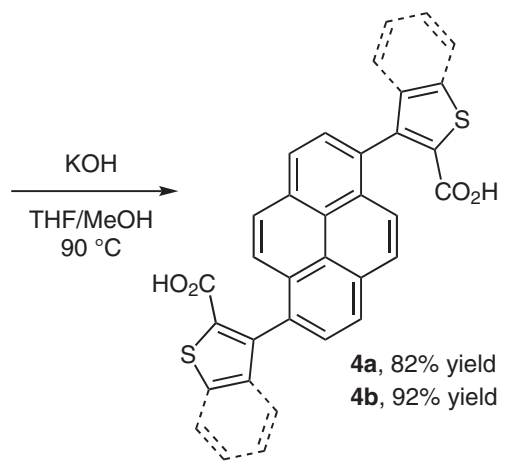

$n$-BuLi, IPSCCH $\mathrm{SnCl}_{2}, \mathrm{HCl}$

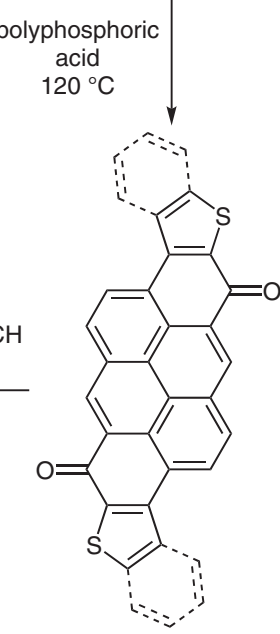

5 a, $92 \%$ yield 5 b, $87 \%$ yield
Significance: Large polycyclic aromatic hydrocarbons (PAHs) with high stability against air and water are highly sought after for the development of new organic electronics. Herein, the authors report two novel 2D bisthienoacenes that exhibit both impressive photostability and air stability. The incorporation of heteroatoms has also led to interesting photophysical properties.
Comment: Compounds $\mathbf{6} \mathbf{a}$ and $\mathbf{6} \mathbf{b}$ provide an interesting addition to the current library of PAHs. The most fascinating feature of these new 2D heteroacenes is the incorporation of a thiophene, which, in the case of $\mathbf{6 a}$, has the potential for further functionalization through the $\alpha$-positions of the annulated thiophenes. This feature transforms 6a into a potentially valuable building block in the development of new polymers with organic electronic applications.

SYNFACTS Contributors: Timothy M. Swager, Monika Stolar Synfacts 2018, 14(12), 1246 Published online: 19.11.2018 DOI: 10.1055/s-0037-1611150; Reg-No.: S11618SF 